\title{
The Relationship Between Air Pollutants and Spirometric Indices in Schoolchildren of Five Areas in Tehran
}

\author{
Siavash Kooranifar', Gholamreza Alizadeh Attar ${ }^{1 *} \mathbb{B}$, Atefeh Talebi', Vahan Moradians', Maryam Pourashraf?', \\ Razieh Rostami ${ }^{3}$, Nima Bakhtiari ${ }^{4}$
}

\author{
'Department of Internal Medicine, School of Medicine, Iran University of Medical Sciences, Tehran, Iran. \\ 2Department of Radiology, School of Medicine, Tehran University of Medical Sciences, Tehran, Iran. \\ ${ }^{3}$ Department of Internal Medicine, School of Medicine, Tehran University of Medical Sciences, Tehran, Iran. \\ 4Pain Research Center, Ahvaz Jundishapur University of Medical Sciences, Ahvaz, Iran. \\ *Correspondence to: Gholamreza Alizadeh Attar (E-mail: sanysasan2002@yahoo.com) \\ (Submitted: 22 July 2021 - Revised version received: 06 August 2021 - Accepted: 29 August 2021 - Published online:26 October 2021)
}

\begin{abstract}
Objectives: The adverse health effects of air pollution have been observed in many epidemiological studies. The aim of this research was to study the effects of air pollution on pulmonary functions in schoolchildren in Tehran city.

Methods: A total number of 167 schoolchildren were selected to participate in this study. Data were analyzed using ANOVA and Generalized Estimating Equation (GEE) to determine the relationship of air pollution and lung function tests.

Results: The result of this study showed that there are statistically significant differences in value of air pollution between areas. The results present that concentration of $\mathrm{O}_{3^{\prime}} \mathrm{PM}_{10^{\prime}} \mathrm{NO}_{2}$ has a negative association with lung function tests but concentration of $\mathrm{CO}_{1} \mathrm{PM}_{2.5^{\prime}}$ and $\mathrm{SO}_{2}$ had no association with decreased lung function tests. Time variable of air pollution was not statistically significant effect on lung function test. Conclusion: in this study, we conclude that air pollution in Tehran city can be decreased lung function test indexes that may be affected by short-time exposure to air pollutant.

Keyword: Lung function, schoolchildren, air pollution, Tehran
\end{abstract}

\section{Introduction}

Air pollutants produced by industrial activities and vehicles such as $\mathrm{O}_{3}, \mathrm{SO}_{2}, \mathrm{NO}_{2}, \mathrm{CO}, \mathrm{PM}_{2.5}, \mathrm{PM}_{10}$ have adverse effects on the respiratory system ${ }^{1,2}$. The adverse effects are more pronounced in children because they are more sensitive when exposed to contaminated air. Children have a lower diameter of airways, and they generally breathe more air per kg of body weight than adults, so exposure to more air pollutants. Increased concentrations of air pollutants cause more inflammation in the respiratory system $^{3,4}$. Children spend more time and more activity outdoor; hence more susceptible to exposure to air pollutants . $^{5}$.

Numerous studies postulated that air pollution had adverse effects on the respiratory system that are more serious in large and industrial cities ${ }^{6}$. Spirometry has been used in several studies to show the effects of air pollution on the respiratory system. Indicators measured by spirometry include FVC, FEV1/FVC, FEV1, MMEF2575, FEV1/FEV6. Most studies examining the short-term effects of air pollution on spirometric indices performed a single spirometry test and have not evaluated changes in spirometric indices during a period, time which are essential in determining the exact effect of air pollutants on the respiratory system ${ }^{7}$.

Therefore, we decided to study the effect of air pollutants on the respiratory system of children by performing two spirometry tests for each child and to evaluate the changes in spirometric indices. Our study was performed in Tehran, the capital city of Iran, which is one of the most polluted cities in this country.

\section{Materials and Methods}

\section{Study Design}

This was a prospective cohort study conducted between September 2018 and May 2019.

\section{Inclusion Criteria}

Students without a history of respiratory disease and recent illness and who were taking no medications were included in this study.

\section{Participants}

In this study, 167 male and female fifth-grade elementary school students, aged between 10 to 12 years old, participated. The students were randomly selected from 10 schools in five municipal districts of the city, which were less than 500 meters from air quality monitoring stations. The height and weight of all of the students were measured. A questionnaire, including questions on drug history, asthma, allergy, eczema, and parent smoking, was given to each student's parents. The study protocol was approved by the Ethics Committee The Iran University of Medical Sciences.

\section{Data on the Levels of Air Pollutants}

The levels of air pollutants such as $\mathrm{O}_{3}, \mathrm{SO}_{2}, \mathrm{NO}_{2}, \mathrm{CO}, \mathrm{PM}_{2.5}$, $\mathrm{PM}_{10}$ were obtained from the Tehran Air Pollution Assessment website $^{8}$. In both first and second episodes of spirometry, the levels of air pollutants were recorded on the day of performing spirometry and five consecutive days before that. The changes in the levels of air pollutants between the first and second episodes of performing spirometry were calculated. Less than 5\% of data on the levels of air pollutants was missed due to technical errors in air monitoring sensors.

\section{Lung Function Test}

Spirometry was performed with a portable spirometer (Spirolab mobile version, China). The spirometer was calibrated using a 3-liter syringe each time before spirometry. Spirometry was performed by expert technicians. In the 
beginning, the spirometry method was fully explained to the students. Three to five spirometry maneuvers were acquired from each student, and the best maneuver was selected based on American Thoracic Society/European Respiratory Society (ERS) criteria.

\section{Statistical Analysis}

The mean daily concentration of air pollutants on the day of the first and second time of spirometry in 5 districts (lag 0 ) and 1-5 days before the first and second time of that (lag 1-5) were measured and compared between five studied sites. Percentage of changes of air pollutant concentration and spirometric indices were calculated between first and second times. In this study, multiple regression using GEE (Generalized Estimating Equation) statistical models were used to determine the correlation between changes of lung function indices (FVC, FEV1, FEV1/FVC, FEV1/FEV6 and FEF25-75) and changes in air pollutants ( 0 days to 5 days before spirometry). Statistical analyses (GEE, ANOVA) were performed using SPSS software (version 22), and statistical significance for $P$-values $<0.05$ were considered.

\section{Consent to Participate}

Written informed consent was obtained from participants before the study.

\section{Ethics Approval}

Ethical approval for the study was obtained by the Ethics Committee of Iran University of Medical Sciences (approval code IR.IUMS.FMD.REC.1397.073). All participants were provided written informed consent before the study and had the right to withdraw from the study at any stage.

\section{Results}

In total, 167 male and female fifth-grade elementary school students, aged between 10 to 12 years old, were included in this study. The students were randomly selected from 10 schools in five districts of the city. The students' characteristics are shown in Table 1. The average and standard deviation (SD) of height, weight, age, and BMI were not different between students of five municipal districts. The results of the mean daily concentrations of air pollutants are displayed in Table 2. The spirometric indices and percentage of changes are presented in Table 3.

The results using GEE (Generalized Estimating Equation) are shown in Table 4. Table 4 shows that a one ppb increase in $\mathrm{O}_{3}$ was associated with a change of $-0.058 \mathrm{~L}$ in FEV1 $(95 \% \mathrm{CI}$ : $-.099--.017 \mathrm{~L})$ and -0.04 in FVC (95\%CI: $-.072--.008 \mathrm{~L})$ and -0.085 Lit in FEF25-75 (95\%CI: -.158- -.012L), after adjustment for gender and height. Our study demonstrates that 1 a ppb increase in $\mathrm{NO}_{2}$ was associated with a change of -0.106 Lit in FEV1 (95\% CI: -.183- -.029L) and -0.087 Lit in FVC (95\% CI: -.149- -.026L), after adjustment for gender and height. This study also displayed that $1 \mu \mathrm{g} / \mathrm{m}^{3}$ increase of $\mathrm{PM}_{10}$ was associated with a change of 0.037 Lit in FEV1 (95\% CI: $.010-.065 \mathrm{~L})$ and $0.039 \mathrm{Lit}$ in FVC (95\% CI: .011 - .068L), after adjustment for gender and height. Other air pollutants had no significant effect on spirometric indices.

\section{Discussion}

The present study included 167 male and female fifth-grade elementary school students, aged between 10 to 12 years. This age range was chosen because of more inadequate cooperation in younger children. This study was conducted on healthy elementary school students without any previous illness.

Air pollutants produced by industrial activities and vehicles such as $\mathrm{O}_{3}, \mathrm{SO}_{2}, \mathrm{NO}_{2}, \mathrm{CO}, \mathrm{PM}_{2.5}, \mathrm{PM}_{10}$ have adverse effects on the respiratory system ${ }^{2}$. Our study assessed the effects of the daily average concentration of air pollutants on spirometric indices. Previous studies have demonstrated that elevated air pollutants were associated with more decrease in lung function in children than adults ${ }^{5}$. Several previous studies have examined the associations between spirometric indices and air pollutants ${ }^{6,9-13}$ but those studies did not consider changes in spirometric indices in individuals. In those studies, the concentration of air pollutants in the days before spirometry was measured.

Chang et al. investigated the effects of air pollution on lung function tests of adolescents aged 12 to 16 years and reported that FVC, had a significant adverse association with short-term exposure to $\mathrm{O}_{3}$ and $\mathrm{PM}_{10}$ measured on the day of spirometry testing ${ }^{13}$.FVC values also were reversely associated with means of $\mathrm{CO}, \mathrm{O}_{3}, \mathrm{NO}_{2}, \mathrm{PM}_{10}$ and $\mathrm{SO}_{2}$ exposed 1 day earlier. An increase of 1-ppm CO was associated with the reduction in FVC for $69.8 \mathrm{~mL}$ (95\% CI: $-115,-24.4 \mathrm{~mL}$ ) or in FEV1 for $73.7 \mathrm{~mL}$ (95\% CI: $-118,-29.7 \mathrm{~mL})$. Their study also showed that an increase in $\mathrm{SO} 2$ for $1 \mathrm{ppb}$ was associated with the reductions in FVC and FEV1 for $12.9 \mathrm{~mL}$ (95\% CI:-20.7, $-5.09 \mathrm{~mL}$ ) and $11.7 \mathrm{~mL}$ (95\% CI:-19.3, -4.16 mL), respectively. Chang et al. similar to other previous studies did not evaluate changes in spirometric indices of each individual during a period, time.

Another difference between The change study and ours was that they found the time lag between the air pollutant measurement and spirometry day, had a significant effect on spirometric indices. nevertheless in our study, there was no significant relationship between the time lag and air pollutant levels. Another study performed by Hashemzadeh et al. in Ahvaz, a major city in the southwest of Iran, demonstrated a

\begin{tabular}{lccccccc}
\hline \multicolumn{7}{l}{ Table 1. Demographic profile of the study participants } \\
\hline Variables & Region2 & Region5 & Region6 & Region7 & Region15 & Total & $\boldsymbol{P}$-value \\
\hline No & 37 & 37 & 31 & 37 & 25 & 167 & \\
Male & $51.30 \%$ & $48.60 \%$ & $35.40 \%$ & $37.80 \%$ & $0 \%$ & $37.10 \%$ & \\
Female & $48.60 \%$ & $51.30 \%$ & $64.50 \%$ & $62.10 \%$ & $100 \%$ & $62.90 \%$ & \\
Height (cm) & $152.6 \pm 7.3$ & $153.4 \pm 8.5$ & $150.2 \pm 10.4$ & $151.3 \pm 8.8$ & $153.2 \pm 7.0$ & $152.0 \pm 8.4$ & $p=0.49$ \\
Weight (kg) & $49.2 \pm 13.4$ & $49.5 \pm 10.5$ & $48.0 \pm 11.3$ & $47.4 \pm 13.6$ & $49.6 \pm 9.5$ & $48.7 \pm 11.8$ & $p=0.92$ \\
BMl & $21.0 \pm 5.0$ & $20.9 \pm 3.5$ & $21.5 \pm 5.3$ & $20.4 \pm 4.0$ & $21.0 \pm 2.6$ & $20.9 \pm 4.2$ & $p=0.90$ \\
\hline
\end{tabular}




\begin{tabular}{|c|c|c|c|c|c|c|}
\hline & Mean (SD) & Mean (SD) & Mean (SD) & Mean (SD) & Mean (SD) & Mean (SD) \\
\hline \multicolumn{7}{|l|}{$\mathrm{SO}_{2}(\mathrm{ppb})$} \\
\hline First time & $3.5 \pm 1.4$ & $3.1 \pm 1.4$ & $3.5 \pm 1.8$ & $3.7 \pm 2.4$ & $4.1 \pm 2.3$ & $4.3 \pm 2.1$ \\
\hline Second time & $4.3 \pm 1.2$ & $4.3 \pm 1.0$ & $4.7 \pm 1.8$ & $3.5 \pm 1.5$ & $3.9 \pm 1.1$ & $3.9 \pm 1.0$ \\
\hline Percentage of changes & $37.6 \pm 51.3$ & $60.4 \pm 62.1$ & $50.3 \pm 55.4$ & $16.5 \pm 51.4$ & $12.9 \pm 59.5$ & $37.6 \pm 51.3$ \\
\hline \multicolumn{7}{|l|}{$\mathrm{NO}_{2}(\mathrm{ppb})$} \\
\hline First time & $45.0 \pm 5.0$ & $42.9 \pm 5.5$ & $43.7 \pm 9.2$ & $45.5 \pm 15.2$ & $43.9 \pm 10.4$ & $47.2 \pm 14.6$ \\
\hline Second time & $49.0 \pm 11.0$ & $48.8 \pm 6.7$ & $47.7 \pm 10.2$ & $41.7 \pm 10.8$ & $44.8 \pm 7.6$ & $49.9 \pm 9.0$ \\
\hline Percentage of changes & $10.2 \pm 20.3$ & $15.4 \pm 18.9$ & $13.2 \pm 25.1$ & $-1.5 \pm 28.3$ & $2.3 \pm 26.5$ & $5.0 \pm 43.4$ \\
\hline \multicolumn{7}{|l|}{ CO (PPM) } \\
\hline First time & $1.4 \pm 0.3$ & $1.3 \pm 0.3$ & $1.3 \pm 0.5$ & $1.5 \pm 0.6$ & $1.3 \pm 0.4$ & $1.7 \pm 0.5$ \\
\hline Second time & $1.7 \pm 0.9$ & $1.7 \pm 0.5$ & $1.4 \pm 0.4$ & $1.3 \pm 0.4$ & $1.4 \pm 0.7$ & $1.5 \pm 0.9$ \\
\hline Percentage of changes & $23.7 \pm 69.4$ & $33.8 \pm 47.2$ & $17.3 \pm 37.5$ & $-6.0 \pm 32.0$ & $1.3 \pm 27.6$ & $-0.2 \pm 60.2$ \\
\hline \multicolumn{7}{|l|}{$\mathrm{O}_{3}(\mathrm{ppb})$} \\
\hline First time & $16.5 \pm 5.5$ & $22.6 \pm 6.6$ & $17.1 \pm 8.5$ & $20.9 \pm 6.7$ & $18.3 \pm 7.4$ & $17.0 \pm 6.3$ \\
\hline Second time & $16.3 \pm 8.5$ & $15.0 \pm 7.5$ & $18.3 \pm 8.9$ & $19.0 \pm 10.7$ & $17.9 \pm 8.9$ & $16.7 \pm 7.0$ \\
\hline Percentage of changes & $-9.3 \pm 43.4$ & $-32 \pm 31.5$ & $-10.8 \pm 43.5$ & $-9.1 \pm 50.7$ & $-3.9 \pm 39.7$ & $11.3 \pm 47.7$ \\
\hline \multicolumn{7}{|l|}{$\mathrm{PM}_{2.5}\left(\mu \mathrm{g} / \mathrm{m}^{3}\right)$} \\
\hline First time & $18.1 \pm 6.9$ & $125.5 \pm 5.1$ & $23.1 \pm 12.5$ & $25.7 \pm 14.5$ & $24.9 \pm 11.6$ & $25.7 \pm 13.8$ \\
\hline Second time & $29.8 \pm 12.6$ & $27.2 \pm 12.5$ & $25.8 \pm 16.4$ & $25.6 \pm 16.1$ & $25.0 \pm 15.3$ & $24.5 \pm 16.7$ \\
\hline Percentage of changes & $72.2 \pm 54.2$ & $87.1 \pm 84.4$ & $22.5 \pm 67.2$ & $6.4 \pm 38.9$ & $10.0 \pm 44.6$ & $28.4 \pm 95.7$ \\
\hline \multicolumn{7}{|l|}{$P M_{10}\left(\mu \mathrm{g} / \mathrm{m}^{3}\right)$} \\
\hline First time & $39.3 \pm 16.2$ & $35.2 \pm 13.8$ & $43.2 \pm 20.8$ & $54.6 \pm 25.4$ & $56.8 \pm 23.2$ & $53.9 \pm 27.0$ \\
\hline Second time & $62.6 \pm 29.0$ & $54.1 \pm 21.7$ & $54.4 \pm 28.7$ & $51.2 \pm 24.1$ & $54.3 \pm 28.0$ & $51.8 \pm 30.1$ \\
\hline Percentage of changes & $78.7 \pm 91.9$ & $70.2 \pm 76.2$ & $42.3 \pm 96.0$ & $-3.7 \pm 38.6$ & $-3.8 \pm 46.5$ & $25.1 \pm 98.9$ \\
\hline
\end{tabular}

\begin{tabular}{lccc}
\hline \multicolumn{4}{l}{ Table 3. The spirometric indices and percentage of changes } \\
\hline & Mean (SD) & Mean (SD) & Mean (SD) \\
\hline FEV1 (L) & $2.1(0.85,3.12)$ & $2.0(0.88,3.02)$ & $-0.5(-61.3,95.2)$ \\
FVC (L) & $2.3(1.21,3.42)$ & $2.2(1.1-3.2)$ & $-2.0(-40.82,57.95)$ \\
FEV1/FVC (\%) & $90.5(40.6,100.0)$ & $90.5(40.6,100.0)$ & $1.6(-54.3,89.8)$ \\
FEV1/FEV6 (\%) & $90.6(40.6,100.0)$ & $91.2(41.3,100.0)$ & $1.4(-54.3,89.8)$ \\
FEF25-75 (L) & $2.7(0.5,4.99)$ & $2.6(0.6,5.3)$ & $5.1(-71.5,160.0)$ \\
\hline
\end{tabular}

\begin{tabular}{lcccccccccc}
\hline \multicolumn{1}{l}{ Table4. The results obtained by Generalized Estimating Equation (GEE) } \\
\hline \multicolumn{1}{c}{} & $\mathbf{B}$ & $\boldsymbol{P}$-value & $\mathbf{B}$ & $\boldsymbol{P}$-value & $\mathbf{B}$ & $\boldsymbol{P}$-value & $\boldsymbol{B}$ & $\boldsymbol{P}$-value & $\boldsymbol{B}$ & $\boldsymbol{P}$-value \\
\hline Time & 0.425 & 0.177 & 0.178 & 0.52 & 0.253 & 0.189 & 0.243 & 0.199 & 0.784 & 0.17 \\
$\mathrm{O}_{3}$ & -0.058 & 0.006 & -0.04 & 0.013 & -0.018 & 0.145 & -0.017 & 0.178 & -0.085 & 0.023 \\
$\mathrm{CO}$ & 0.003 & 0.856 & -0.005 & 0.78 & 0.009 & 0.337 & 0.009 & 0.333 & 0.019 & 0.516 \\
$\mathrm{NO}_{2}$ & -0.106 & 0.007 & -0.087 & 0.005 & -0.018 & 0.531 & -0.014 & 0.614 & -0.134 & 0.167 \\
$\mathrm{SO}_{2}$ & 0.028 & 0.127 & 0.011 & 0.462 & 0.017 & 0.139 & 0.017 & 0.135 & 0.025 & 0.46 \\
$\mathrm{PM}_{10}$ & 0.037 & 0.008 & 0.039 & 0.007 & -0.003 & 0.679 & -0.004 & 0.611 & 0.025 & 0.344 \\
$\mathrm{PM}_{2.5}$ & -0.009 & 0.616 & -0.021 & 0.222 & 0.013 & 0.117 & 0.012 & 0.142 & 0.026 & 0.371 \\
\hline
\end{tabular}


significant correlation between the increase of mean concentration of $\mathrm{NO}_{2}$ in 1 to 4 days before sampling day and decreased FVC and FEV $1^{14}$. In this regard, by increasing the mean $\mathrm{NO}_{2}$ concentration to $6.5 \mathrm{ppb}$, the values of FVC and FEV1 decreased by 12 and $19 \mathrm{~mL}$; and by increasing the mean concentration of $\mathrm{PM}_{25}$ to $13 \mu \mathrm{g} / \mathrm{m}^{3}$ on the same day of sampling (lag 0), the values of FVC and FEV1 decreased by 131 and 110 ml. However, similar to most previous studies, they did not evaluate spirometric changes within a period, time.

In our study, Ozone harmed FEV1, FVC and FEF25-75, with the most significant effect on FEF25-75.It should be noted that although these effects are statistically significant, they are clinically insignificant and they did not cause symptoms in the students.

In normal subjects, the cut-off for clinically significant week-to-week changes of FEV1 and FVC were more than 12\% and $11 \%$, respectively. In our study, $61.6 \%$ of the subjects had FEV1 change less than $12 \%$ and $63.4 \%$ had FVC change less than $11 \%$. In fact, in most subjects, although the percentage of spirometric changes was statistically significant, the indices remained within the normal range.

\section{Conclusion}

Our research suggests that air pollution in Tehran city can lead to decreased lung function test indices which may be affected by short-time exposure to air pollutants. Traffic-related air pollutants show acute and subacute adveres effects on the respiratory system in school children. Accordingly, our research suggests air pollution changes are associated with changes in lung function in a healthy subject. These findings can help improve understanding adverse effects of air pollution on the respiratory system, and may also implicatemore targeted and effective pollution regulations to reduce traffic emission pollutants.

\section{Acknowledgment}

This work would not have been possible without the financial support of the Pasargad Teb IrsaCompany Award.

\section{Declarations}

Funding/Support: This research was funded by Iran University of medical sciences by grant number 805 as part of thesis of Gholamreza Alizadeh Attar.

Competing Interests: The authors have no conflict of interest.

Data Availability: The datasets used in the present study are available from the corresponding author on reasonable request.

Authors' Contributions: All authors contributed to the study conception and design. Material preparation, data collection and analysis were performed by Gholamreza Alizadeh Attar. The first draft of the manuscript was written by Gholamreza Alizadeh Attar and all authors revisedthe previous versions of the manuscript. All authors read and approved the final manuscript.

\section{References}

1. Zhang, Y., et al., Short-term effects of fine particulate matter and temperature on lung function among healthy college students in Wuhan, China. International journal of environmental research and public health, 2015. 12(7): p. 7777-7793.

2. Hassanvand, M.S., et al., Short-term effects of particle size fractions on circulating biomarkers of inflammation in a panel of elderly subjects and healthy young adults. Environmental pollution, 2017. 223: p. 695-704.

3. Gasana, J., et al., Motor vehicle air pollution and asthma in children: a metaanalysis. Environmental research, 2012. 117: p. 36-45.

4. Kampa, M. and E. Castanas, Human health effects of air pollution. Environmental pollution, 2008. 151(2): p. 362-367.

5. Lee, Y.L., et al., Effects of ambient air pollution on pulmonary function among schoolchildren. International journal of hygiene and environmental health, 2011. 214(5): p. 369-375.

6. Zeng, X.-W., et al., Long-term ambient air pollution and lung function impairment in Chinese children from a high air pollution range area: The Seven Northeastern Cities (SNEC) study. Atmospheric Environment, 2016. 138: p. 144-151.

7. Linares, B., et al., Impact of air pollution on pulmonary function and respiratory symptoms in children. Longitudinal repeated-measures study. BMC Pulmonary Medicine, 2010. 10(1): p. 1-9.

8. Company, T.A.Q.C. http://airnow.tehran.ir/home/DataArchive.aspx. 2020; Available from: https://air.tehran.ir/.

9. Arora, S., et al., Air pollution and environmental risk factors for altered lung function among adult women of an urban slum area of Delhi: A prevalence study. Lung India: Official Organ of Indian Chest Society, 2018. 35(3): p. 193.

10. Wu, S., et al., Association of lung function in a panel of young healthy adults with various chemical components of ambient fine particulate air pollution in Beijing, China. Atmospheric Environment, 2013. 77: p. 873-884.

11. He, Q.-Q., et al., Effects of ambient air pollution on lung function growth in Chinese schoolchildren. Respiratory medicine, 2010. 104(10): p. 1512-1520.

12. Kasamatsu, J., et al., Effects of winter air pollution on pulmonary function of school children in Shenyang, China. International journal of hygiene and environmental health, 2006. 209(5): p. 435-444.

13. Chang, Y.-K., et al., The short-term effects of air pollution on adolescent lung function in Taiwan. Chemosphere, 2012. 87(1): p. 26-30.

14. Hashemzadeh, B., et al., Effects of PM2. 5 and NO2 on the 8-isoprostane and lung function indices of FVC and FEV1 in students of Ahvaz city, Iran. Saudi journal of biological sciences, 2019. 26(3): p. 473-480. 